\title{
Two Techniques for the Preparation of Cell-Scaffold Constructs Suitable for Sinus Augmentation: Steps into Clinical Application
}

\author{
INGO N. SPRINGER, ${ }^{1}$ PIER F. NOCINI, ${ }^{2}$ KARL A. SCHLEGEL, ${ }^{3}$ \\ DANIELE DE SANTIS, ${ }^{2}$ JUNG PARK, ${ }^{3}$ PATRICK H. WARNKE, ${ }^{1}$ HENDRIK TERHEYDEN, ${ }^{1}$ \\ ROBERT ZIMMERMANN, ${ }^{4}$ LUIGI CHIARINI, ${ }^{5}$ KLAUS GARDNER, ${ }^{3}$ FRANCESCA FERRARI, ${ }^{2}$ \\ and JÖRG WILTFANG ${ }^{1}$
}

\begin{abstract}
The objective of this clinical trial was the analysis of 2 methods for engineering of autologous bone grafts for maxillary sinus augmentation with secondary implant placement. Group 1 (8 patients, 12 sinuses): cells of mandibular periosteum were cultured in a good manufacturing practice laboratory ( 2 weeks) with autologous serum and then transferred onto a collagen matrix. After another week, these composites were transplanted into the sinuses. In group $2 \mathrm{~A}$ ( 2 patients, 3 sinuses), cells of maxillary bone were cultivated with autologous serum for 2 weeks, seeded onto natural bone mineral (NBM, diameter $[\emptyset]=8 \mathrm{~mm}$ ) blocks, and cultivated for another 1.5 months. These composites were transplanted into the sinuses. Group 2B (control, 3 patients, 5 sinuses) received NBM blocks alone. In the course of implant placement 6 (group 1) and 8 (group 2) months later, core biopsy were taken. Clinical follow-up period was 1 to 2.5 years in group 1 and approximately 7 years in groups $2 \mathrm{~A}$ and $2 \mathrm{~B}$. New vital bone was found in all cases at median densities of $38 \%(n=12)$ in group $1,32 \%$ in group $2 A(n=3)$, and $25 \%$ in group 2B $(n=5)$. Differences between group 1 and $2 B$ as well as $2 A$ and $2 B$ were statistically significant $(p=0.025)$. No adverse effects were seen. All methods described were capable of creating new bone tissue with sufficient stability for successful implant placement.
\end{abstract}

\section{INTRODUCTION}

A UTOGENOUS BONE GRAFTS are considered to be osteoconductive and osteoinductive. Autogenous bone grafting remains the gold standard for the augmentation of the maxillary sinus before placement of dental implants. ${ }^{1-6}$

It is desirable to avoid harvesting of excessive amounts of bone to reduce donor site morbidity. ${ }^{7}$ Non-vital bone substitutes such as xenogenic deproteinized natural bone mineral (NBM, BioOss, Geistlich Pharma AG, Wolhusen, Switzerland) or others avoid bone harvesting but are sup- posed to have a narrow range of use and limited potential of osteoconduction. ${ }^{8,9}$ Requisites for the use of NBM include the proximity of vital bone and a good blood supply. These requirements are present in the sinus lift model. ${ }^{10}$ Methods of tissue engineering and the application of differentiation factors such as bone morphogenetic protein have seen significant advances in recent times. ${ }^{11-14}$ In a clinical trial involving sinus floor augmentation, it was reported that platelet-rich plasma could support bone regeneration when added to beta-tricalciumphosphate (beta-TCP). ${ }^{15}$ The combination of non-vital bone substitutes and autogenous

\footnotetext{
${ }^{1}$ Department of Oral and Maxillofacial Surgery, University of Schleswig-Holstein, Campus Kiel, Kiel, Germany.

${ }^{2}$ Department of Morphological and Biomedical Sciences, Dental and Maxillofacial Department, University of Verona Medical School, Verona, Italy.

${ }^{3}$ Department of Oral and Maxillofacial Surgery, University of Erlangen-Nuremberg, Erlangen, Germany.

${ }^{4}$ Department of Transfusion Medicine, University of Erlangen-Nuremberg, Erlangen, Germany.

${ }^{5}$ Azienda Policlinico Dipartimento Neuroscienze Testa-collo e Riabilitazione, Modena, Italy.
} 
bone precursor cells or osteoblasts may provide a further option for sinus augmentation.

The aim of the present trial was the comparative study of an ex vivo tissue-engineered combination of a collagen matrix and autologous periosteal cells and the ex vivo tissueengineered combination of NBM with autologous osteoblasts in a sinus augmentation procedure with secondary implant placement.

\section{MATERIALS AND METHODS}

The following patient groups with atrophy of the posterior maxilla were studied (Table 1):

Group 1: Combination of periosteum-derived cells with a collagen matrix; $n=8$ patients ( 4 male, 4 female, age: 51.4-65.2 years, mean 57.8 years), $n=12$ sinus augmentation procedures ( 3 bilateral), $n=30$ core biopsies; time of implant placement: 6 months; implant: Replace Select Straight (Nobel Biocar, Köln, Germany); clinical follow-up period: 1-2.5 years.

Group 2A: Combination of autologous osteoblasts and xenogenic NBM blocks (BioOss, $\varnothing=8 \mathrm{~mm}$ ), $n=2$ patients (age: $43 / 56$ years), $n=3$ sinus augmentation procedures ( 1 bilateral), $n=3$ core biopsies; time of implant placement: 8 months; implants: Sustain-HA-"Plasma sprayed" implants (Lifecore Biomedical, Sascha, MN); clinical follow-up period: 7 years.

Group 2B: NBM alone (control), $n=3$ patients (age: $46-58$ years), $n=5$ sinus augmentation procedures ( 2 bilateral), $n=5$ core biopsies; time of implant placement: 8 months; implants: Sustain-HA-"Plasma sprayed" implants (Lifecore Biomedical); clinical follow-up period: 7 years.

\section{Harvesting of autologous tissue and cell culture group 1}

Four hundred fifty $\mathrm{mL}$ of whole blood was drawn, and $100 \mathrm{~mL}$ autologous serum was generated 2 days before initial surgery. Periosteum $(1 \times 1 \mathrm{~cm})$ was taken from the lateral cortex of the mandibular angle with local anesthesia and processed in a Good Manufacturing Practice laboratory. Periosteal tissue was divided into small fragments and digested with $0.25 \%$ collagenase $\mathrm{P}$ (Sigma, Germany) in alpha medium (Invitrogen, Karlsruhe, Germany) for $4 \mathrm{~h}$ at $37^{\circ} \mathrm{C}$ and filtered through a $70-\mu \mathrm{m}$ cell strainer (Falcon). The cell filtrate was centrifuged at $1800 \mathrm{rpm}$ for $10 \mathrm{~min}$. Pellets were resuspended in alpha medium supplemented with $20 \%$ patient serum and $100 \mathrm{U} / \mathrm{mL}$ penicillin $\mathrm{G}, 100 \mu \mathrm{g} / \mathrm{mL}$ streptomycin, and $0.25 \mu \mathrm{g} / \mathrm{mL}$ amphotericin (Invitrogen). The cell number was counted, and cells were plated in a $75-\mathrm{cm}^{2}$ flask and incubated at $37^{\circ} \mathrm{C}$ with $5 \%$ carbon dioxide. The medium was replaced every 2 days. After reaching confluence, cells were trypsinized with a $0.25 \%$ trypsin/ethylenediaminetetraacetic acid solution (Invitrogen). The cells were subcultured again at day 8 to day 11 and seeded on to a collagen scaffold $\left(1.5 \times 10^{5}\right.$ cells $\left./ \mathrm{cm}^{2}\right)$ (Lyostypt, Braun) at day 12 to day 15 . Four of these composites $(2 \times 3.5 \mathrm{~cm}$ in size $)$ were prepared for each sinus and cultivated with differentiation medium (alpha medium containing 10\% patient serum, $100 \mathrm{nM}$ dexamethasone, $10 \mu \mathrm{M} \beta$-glycerophosphate, $25 \mu \mathrm{g} / \mathrm{mL}$ ascorbic acid, $100 \mathrm{U} / \mathrm{mL}$ penicillin $\mathrm{G}, 100 \mu \mathrm{g} / \mathrm{mL}$ streptomycin, and $0.25 \mu \mathrm{g} / \mathrm{mL}$ amphotericin) for another 5 to 7 days. This amounted to a total of approximately 21 days between harvesting of periosteum and sinus augmentation with the composites.

\section{Harvesting of autologous tissue and cell culture group 2}

Blood was drawn, and autologous serum was generated. Autologous bone was taken from the maxillary tuberosity. ${ }^{16}$ The bone chips were processed as described previously ${ }^{1,17,18}$ in modified standard Dulbecco's modified Eagle medium (ICN-flow, Sigma, St. Louis, MO) replacing fetal bovine serum with human autologous serum. ${ }^{17}$ After 2 weeks of in vitro culture, the osteoblast-like cells were inoculated in F75 plastic tissue culture flasks (Falcon, Becton-Dickinson \& Co., Plymouth, UK). After another week, sub-confluence was reached, and the osteoblast-like cells were seeded onto cubic fragments of Bio-Oss $(\varnothing=$ $8 \mathrm{~mm}$ ) of approximately $8 \mathrm{~mm}^{3}$ at a density of $3.3 \times 10^{6} \%$ $\mathrm{cm}^{2}$ and were cultivated for another 40 days on 24-well plates (Costar). To determine alkaline phosphatase (ALP) activity, cells were seeded at $1 \times 10^{3}$ cells $/ \mathrm{cm}^{2}$ in Lab-Tek chamber slides (Nunc, Denmark), and cultured for 3 days. ALP activity was determined using cytochemistry with the Sigma Diagnostic Kit (86-R, Deisenhofen, Germany), as described previously. ${ }^{1}$

Table 1. Patients with Atrophy of the Posterior Maxilla Were Studied

\begin{tabular}{lllccccc}
\hline Group & $\begin{array}{c}\text { Origin } \\
\text { of cells }\end{array}$ & Matrix & $\begin{array}{c}\text { Patients } \\
(\mathrm{n})\end{array}$ & $\begin{array}{c}\text { Sinus } \\
\text { augmentation } \\
\text { procedure (n) }\end{array}$ & $\begin{array}{c}\text { Biopsies } \\
(\mathrm{n})\end{array}$ & $\begin{array}{c}\text { Time of implant } \\
\text { placement (months) }\end{array}$ & $\begin{array}{c}\text { Follow-up } \\
\text { period (years) }\end{array}$ \\
\hline 1 & Periosteum & Collagen & 8 & 12 & 30 & 6 & $1-2.5$ \\
$2 \mathrm{~A}$ & Bone & NBM & 2 & 3 & 3 & 8 & 7 \\
2B & None & NBM & 3 & 5 & 5 & 8 & 7 \\
\hline
\end{tabular}

Details and implant types are described within the materials and methods section. NBM, xenogenic natural bone mineral blocks (BioOss). 


\section{Sinus augmentation}

All surgical procedures were performed in the outpatient clinic using local anesthesia. A crestal incision was used, vertically extended down to the mobile mucosal border, and the facial aspect of the sinus wall was exposed. With reference to the virtual apex line, the inferior border of the lateral window was marked using round burs. After removal of the bone, the sinus membrane was elevated. Then tissueengineered bone substitutes (group 1: 4 cell + collagencomposites/sinus; group 2A: 12-14 cell + NBM composites/ sinus; group 2B: NBM granula $[\varnothing=1-2-\mathrm{mm}]$ ) were implanted, and the soft tissue was repositioned and sutured with 5-0 Vicryl (Ethicon GmbH, Norderstedt, Germany). On the tenth postoperative day, the sutures were removed. In all cases, the postoperative healing was uneventful. After 6 months, core biopsies were taken using hollow trephine burs $(3.5 \times 6 \mathrm{~mm})$ in the course of implantation. Each patient received at least 2 implants per augmented area. (For number of implants and core biopsy, see above.)

\section{Histology}

Preparation of non-decalcified specimens and histological analysis was performed as described previously. ${ }^{19-21}$ Specimens were dehydrated in a graded fashion with alcohol and embedded in methylmethacrylate blocks. Nondecalcified serial sections were prepared and ground to a width of $80 \mu \mathrm{m}$ for microradiography and a $8 \mu \mathrm{m}$ for staining (Toluidine-blue). ${ }^{19-21}$ In group $2 \mathrm{~A}$ and $2 \mathrm{~B}, 80-\mu \mathrm{m}$ sections were prepared and stained with toluidine blue and basic fuchsin. Viable bone stains more intensely than NBM when using toluidine blue and basic fuchsin (Fig. 1). The presence of osteocytes could further help to identify viable bone.

Microradiography was performed for samples from group 1 ( $3 \mathrm{mAs}, 25 \mathrm{kV}$, time of exposure: $10 \mathrm{~min}$, material: high resolution plates, Kodak, Faxitron, Rohde and Schwarz GmbH and CoKG, Köln, Germany) ${ }^{20}$ and the images analyzed using a digital image analyzing system (group 1: Osiris program, digital imaging unit, Center for Medical Informatics, University of Geneva, Switzerland; group 2: Image J 1.32, National Institutes of Health). Specifically, the bone-covered space in the region of interest was analyzed with respect to the non-mineralized medullary space in percentage of mineralized bone matrix per area ( 3 repeats, variation $<2 \%$, magnification: 40x)(bone density; unit: [\%]). ${ }^{20,22,23}$

\section{Statistics}

Statistical evaluation was performed according to KruskalWallis to detect differences between groups 1, 2A, and 2B. Two-tailed Mann-Whitney U-tests served to evaluate differences between groups 1 and $2 \mathrm{~A}$ and groups $2 \mathrm{~A}$ and $2 \mathrm{~B}$, as well as differences between female and male patients of group 1 . Level of significance was defined at $p<0.05$.

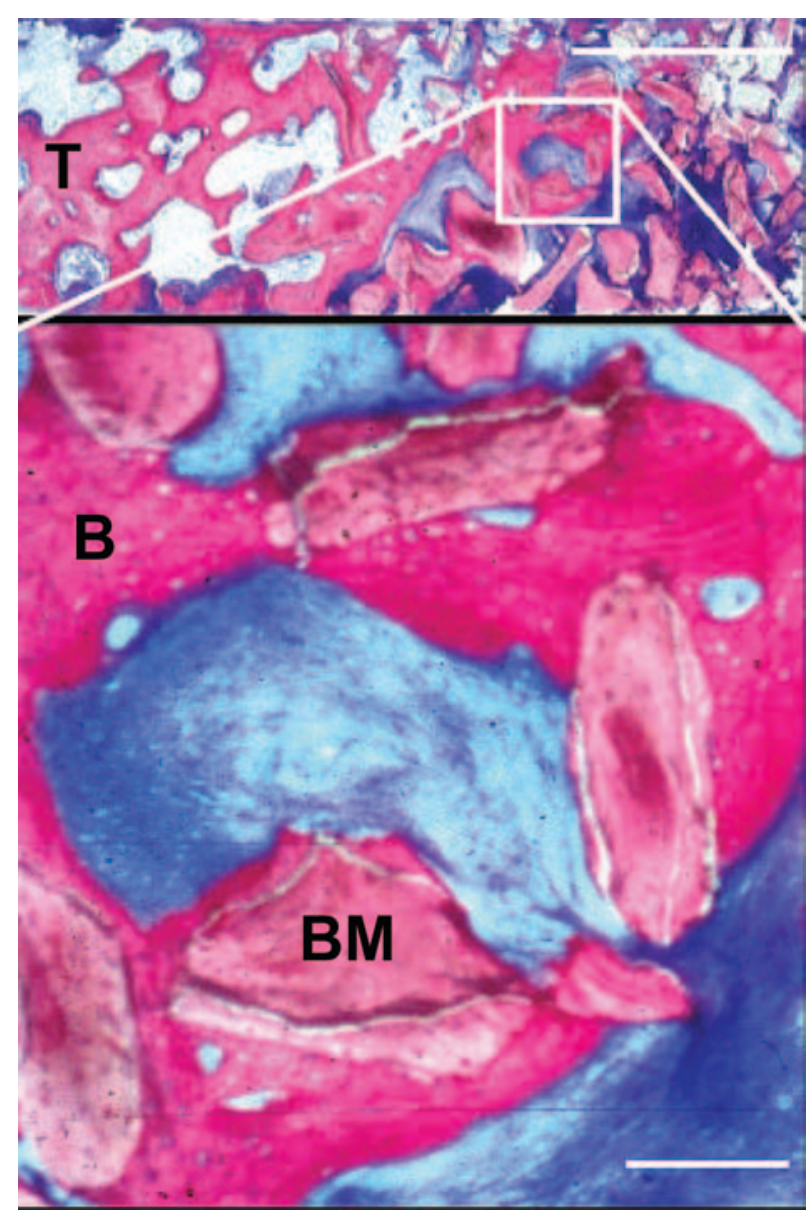

FIG. 1. Core biopsy (T) of group 2A. Toluidine blue and basic fuchsin stain of an $80-\mu \mathrm{m}$ non-decalcified section. The higher magnification showed natural bone mineral (NBM) particles (BM) incorporated by newly formed bone (B), the latter of which is stained darker than NBM particles. Upper line: $2 \mathrm{~mm}$, lower line: $200 \mu \mathrm{m}$. Color images available online at www.liebertpub.com/ ten.

\section{Ethics}

The ethics committee of the University of Erlangen (group 1, approval no. 2741-2001) and the Centro Nazionale per la Ricerca (group 2, approval no. 95.02288.CT041995, Veneta Health Research Project number 1798 of 23.4.1996) approved the study.

\section{RESULTS}

\section{Cell culture group 1}

At day 5 through day 8 after the first passage, an average of $1 \times 10^{6}$ adherent cells were present. Cell numbers increased to more than 20 million during the second week (average $\left.2.1 \times 10^{7}\right)$. At day 12 to day 15 , cells were harvested and implanted into a collagen matrix (Lyostypt, Braun) at a density of $1.5 \times 10^{5} / \mathrm{cm}^{2}$. Approximately 6 million cells were 
implanted into 4 sheets of collagen $(4 \times 2.5 \mathrm{~cm}$ in size $)$. After another week of culture, 4 sheets of collagen were transferred into each sinus.

\section{Cell culture group $2 A$}

Cells were subcultured to a density of $3.3 \times 10^{6} / \mathrm{cm}^{2}$ before being transferred onto the NBM blocks. Cells were defined as osteoblast-like cells by presence of ALP activity. The total number of cells implanted into each sinus could not be estimated because the cell/NBM composites were subcultured for another 40 days.

\section{Clinical results}

All first-stage and second-stage surgeries were uneventful. No infection was observed. Re-entry surgery was executed 6 months (group 1) and 8 months (groups 2A and B) after sinus augmentation. At this time, a sufficient quantity of mineralized tissue was found in groups 1 (Fig. 2), 2A (Fig. 3), and 2B. Dental implants were placed without the need for further bone augmentation (Figs. 2, 3). Implants were left unloaded for 4 to 5 months before prosthetic rehabilitation. None of the implants were lost in the observation period (group 1: 12-38 months, groups 2A, B: 7 years). All implants remained firmly osseointegrated throughout the experimental period.

\section{Light microscopy}

Core biopsy of group 1 showed vital woven and partly mature lamellar bone (Fig. 4). Little of the collagen matrix remained.

Core biopsy of group 2A showed that NBM particles were incorporated in newly formed bone in the inferior part (facing the former floor of the sinus) of the bone core ( $\sim 80 \%$ of bone core length) (Fig. 1). At the top of the biopsy ( $\sim 20 \%$ ) poorly vascularized, dense connective tissue surrounded NBM particles.

Core biopsy of group 2B showed bone cores with NBM particles integrated with vital new bone. The density of newly formed bone was significantly lower than in group 2A (see below).

\section{Density of new bone within the former cell-carrier composites}

Group 1: The median bone density (mineralized tissue) was $38 \%$ (minimum: $30 \%$, maximum: $51 \%$ ). Female patients $(n=4)$ had a tendency toward lower average bone densities (median: 33\%; minimum: 31\%, maximum: $34 \%$ ) than male patients $(n=4$; median: $40 \%$; minimum: $30 \%$, maximum: $51 \%)$. These differences were not statistically significant ( $p=0.245$; Fig. 5).

Group 2A: The median density of newly formed bone (disregarding NBM) was 32\% (minimum: 30\%, maximum:
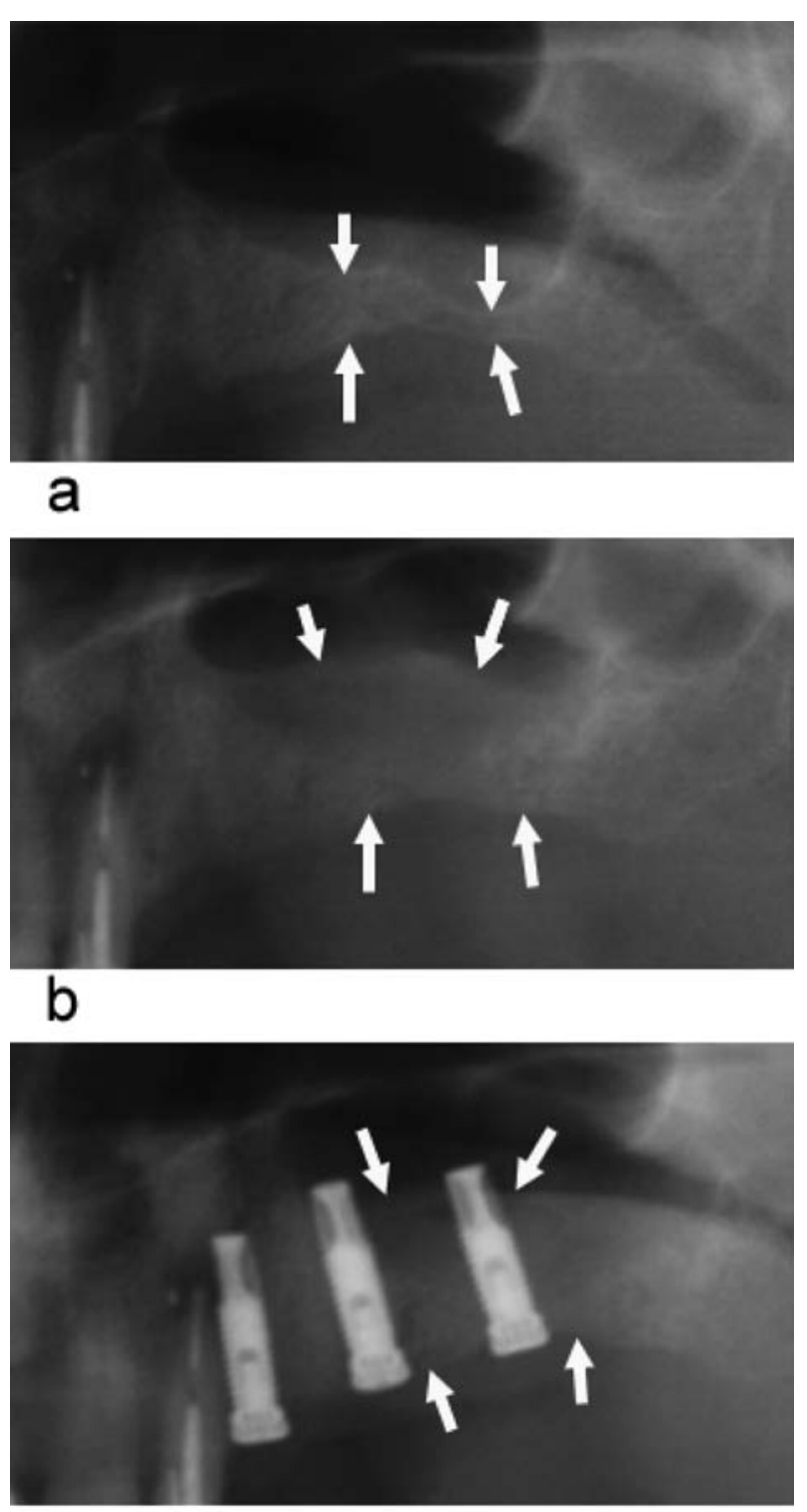

C

FIG. 2. Radiographs of a patient in group 1 before surgery (A), 6 months later $(\mathbf{B})$, and after implant placement $(\mathbf{C})$. At the time of implant placement $(\mathbf{B})$, a sufficient quantity of mineralized tissue was found, and core biopsy showed new vital bone (Fig. 4). Arrows show the floor of the sinus (point down) and limbus of the alveolar ridge (point up).

$37 \%$ ). The median density of the complete mineralized tissue (newly formed bone + NBM) was $43 \%$ (minimum: 34\%, maximum: 45\%; Fig. 5).

Group 2B: The median density of newly formed bone was 25\% (minimum: $22 \%$, maximum: $26 \%$ ). The median density of complete mineralized tissue (newly formed bone + NBM) was $38 \%$ (minimum: $35 \%$, maximum: $70 \%$; Fig. 5).

The Kruskal-Wallis test revealed significant differences of density of newly formed bone between groups 1, 2A, and 2B $(p=0.01)$. Differences between densities of newly 


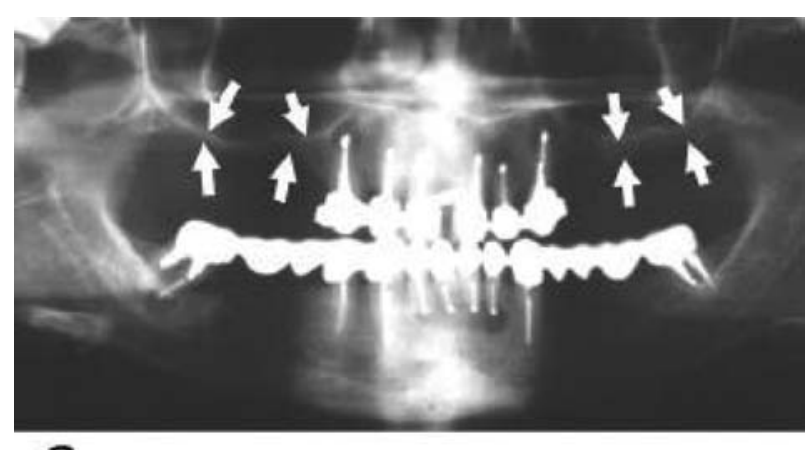

a

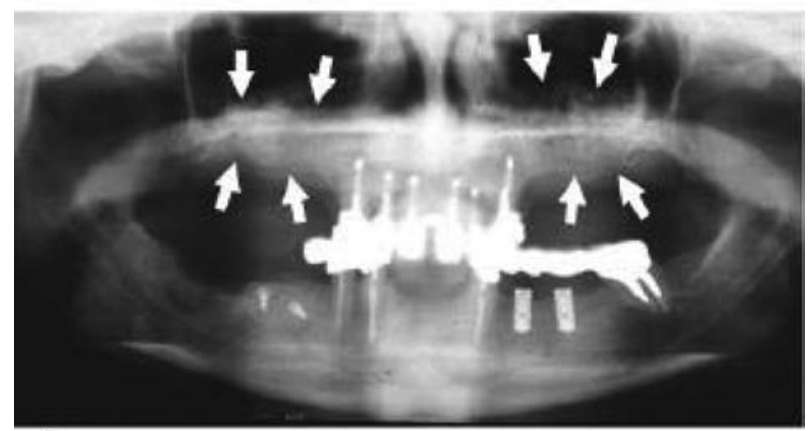

b

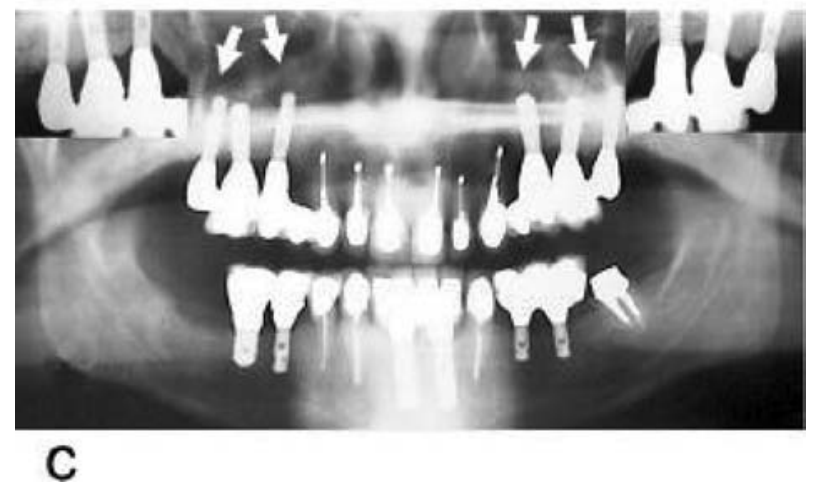

FIG. 3. Radiographs of a patient in group 2 before surgery (A), 6 months later $(\mathbf{B})$, and 7 years after implant placement $(\mathbf{C})$. At the time of implant placement, a sufficient quantity of mineralized tissue was found, and core biopsy showed new vital bone (Fig. 1). Arrows show the floor of the sinus (point down) and limbus of the alveolar ridge (point up).

formed bone between group 2A (cells $+\mathrm{NBM}$ ) and 2B (NBM) were statistically significant $(p=0.025)$. Differences of densities of newly formed bone between groups 1 (cells + collagen) and 2A (cells $+\mathrm{NBM})$ were not statistically significant $(p=0.18)$.

\section{DISCUSSION}

The aim of the present trial was to take steps into clinical application of bone engineering techniques. The clinical value of an ex vivo tissue-engineered combination of a

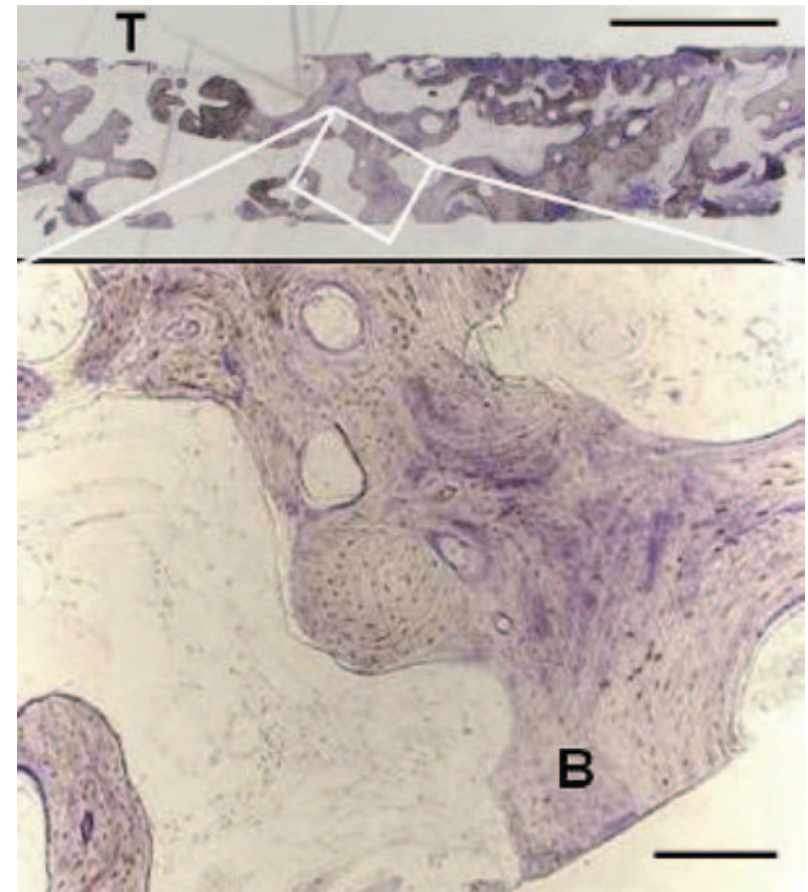

FIG. 4. Core biopsy (T) of group 1. Toluidine blue stain of an $8-\mu \mathrm{m}$ non-decalcified section. The higher magnification shows vital woven and partly mature lamellar bone (B). Upper line: $2 \mathrm{~mm}$, lower line: $200 \mu \mathrm{m}$. Color images available online at www.liebert pub.com/ten.

collagen matrix with autologous periosteal cells and the ex vivo tissue-engineered combination of NBM with autologous osteoblasts was studied in patients in need of sinus augmentation procedures. Implants were placed in a second-stage surgery after 6 to 8 months because the alveolar bone was not providing conditions offering primary stability of the implants in these patients. ${ }^{24}$

Methods of in vitro and in vivo tissue engineering of bone and cartilage have been evaluated in a variety of experiments, all showing potentials and limitations of these methods. ${ }^{18,25-27}$ A major concern is the use of the proper carrier matrix.

It has been suggested that absorbable scaffolds made of the combination of undyed Vicryl (Polyglactin 910) and undyed poly-p-dioxanon (Ethisorb fleece) or made of polyglycolic acid fibers $15 \mu \mathrm{m}$ in diameter would be ideal for tissue engineering of bone and cartilage. ${ }^{13,14,28}$

There has been some concern about these polymers regarding decline in $\mathrm{pH}$ value during the degradation of the polymers, which again, among many other shortfalls, may bring about impaired cellular function and inhibition of neoangiogenesis. ${ }^{13,29-31}$ Four months after posterior maxillary augmentation with a combination of periosteumderived cells and Ethisorb fleece as a carrier material, other authors observed sufficient osteogenesis in 18 of 27 patients. ${ }^{13}$ We tested the value of a variety of biomaterials for the purpose of bone engineering in the course of an in vitro 


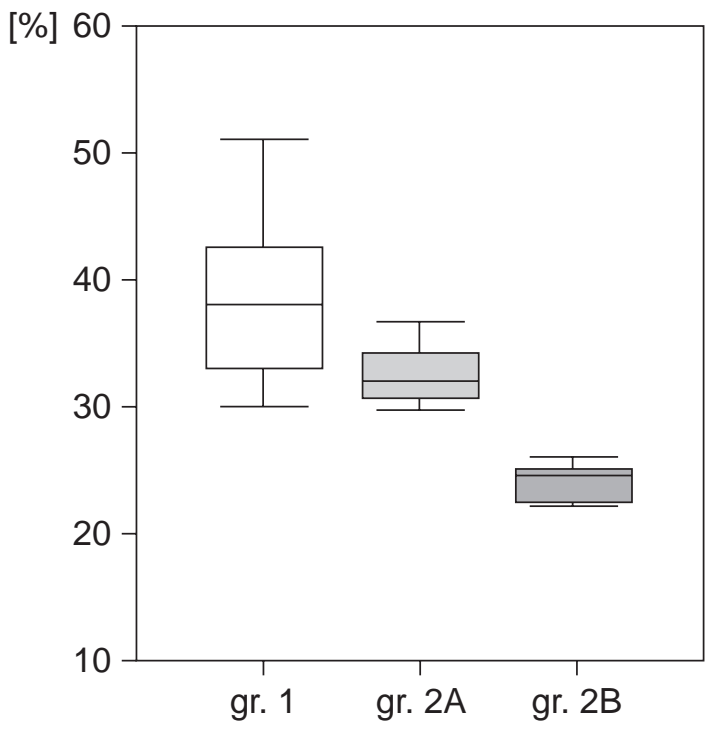

FIG. 5. Box plot (median, 1 and 3 quartile, range) showing densities of newly formed bone of group 1 (cells + collagen), group 2A (cells + natural bone mineral $[\mathrm{NBM}]$ ) and group $2 \mathrm{~B}$ (NBM). When adding densities of remaining NBM to the bone densities of newly formed bone, total densities of mineralized tissues were $43 \%$ in group $2 \mathrm{~A}$ and $38 \%$ in group $2 \mathrm{~B}$.

experiment and found 3-dimensional collagen scaffolds to be most advantageous. ${ }^{32}$ Collagen is a significant constituent of the natural extracellular matrix of bone and most other tissues. ${ }^{33}$ Hemostatic properties, low antigenicity, and moderate internal stability are some of its properties. ${ }^{34}$ Collagen scaffolds have been observed to promote cell attachment, as well as 3-dimensional spread, and one follows the course of natural de novo bone formation when using collagen scaffolds for bone engineering. ${ }^{35,36}$

In group 1 of the present trial, a collagen matrix was used for tissue engineering, resulting in bone formation in all 30 regions that were biopsied using a hollow trephine burr. The mineralization rates were comparable with those reached when using anterior and posterior iliac bone. Based on the low number of patients $(n=8)$, the technique used in group 1 appeared to have predictable results over a limited time of follow-up.

Biomaterials such as xenogenous NBM provide good internal stability of the implant, but complete absorption is prolonged if not impossible. ${ }^{10,37,38} \mathrm{NBM}$ is a finely crystalline apatite composed of calcium carbonate crystals sized 100 to $400 \AA$ and arranged in a trabecular structure (pore size: $300-1500 \mu \mathrm{m})$ that is highly porous $(70-75 \%) .{ }^{38} \mathrm{NBM}$ and other bone substitutes are considered to be osteoconductive but not osteoinductive. ${ }^{9}$ Autogenous bone grafts are considered to be osteoconductive and osteoinductive and remain the gold standard in bone regeneration. ${ }^{3}$ Neither xenogenic collagen nor NBM has a risk of transmitting Creutzfeldt Jakob Disease. ${ }^{37}$ To avoid the potential risk of transmitting prion diseases, autologous human serum in- stead of fetal calf serum was used for the in vitro phases of this trial. 39

In the course of the in vitro phase of group 2A, we confirmed again that osteoblast-like cells seeded on NBM spread and express typical markers indicating osteoblastlike differentiation, such as ALP. ${ }^{18,40}$ ALP is an enzyme considered to be important in the process of biomineralization. ${ }^{18,40}$ The patients tolerated the tissue-engineered grafts well, and sufficient mechanical anchorage was established for implant placement and loading. A limited number of procedures $(n=3)$ and patients $(n=2)$, but a 7-year follow-up period, support these results.

In group 1 (cells + collagen) and group 2B (cells + NBM), equivalent amounts of newly formed bone were observed. The density was not significantly different between these groups but was statistically significantly higher in group 1 and $2 \mathrm{~A}$ than in group 2B (NBM). When adding densities of remaining NBM to the bone densities of newly formed bone, total densities of mineralized tissues were $43 \%$ in group $2 \mathrm{~A}$ and $38 \%$ in group $2 \mathrm{~B}$. It remains controversial whether the remaining NBM contributes to the mechanical stability of the bony regenerate. ${ }^{10}$

A limitation of this study was the low number of procedures and patients, especially in group 2A. An advantage was a follow-up period of 7 years (group 2), showing no implant failure and suggesting that ex vivo tissue-engineered bone made using osteoblasts and NBM might be a clinical option. More patients were enrolled in groups 1 and $2 \mathrm{~B}$. The observation period of 1 to 2.5 years in group 1 showed promising results with no implant loss. To meet statistical criteria, we chose medians and mean ranks for data analysis. Statistical analysis according to Kruskal-Wallis and the Mann-Whitney U test are considered to be common methods for small groups of samples.

Bone grafts, possibly mixed with NBM, have been considered to provide the most predictable results in the course of sinus augmentation procedures. NBM has no osteoinductive properties. In former studies, we showed that the addition of osteoinductive proteins or bone to NBM improved the bone-implant contact (i.e., the osseointegration of implants) significantly, with the direct coverage of the implant by newly formed bone being improved approximately $100 \% .^{10,41}$ The use of vital bone transplants is known to reduce healing times and the time between augmentation and implantation in cases of 2-step procedures. We suggest that it is worthwhile to investigate new methods of engineering bone transplants to save patients a second site of invasive surgery, even when one is facing immense time and effort for the patient and the doctor. Considering the present technical possibilities, it will be difficult to shorten the time needed to prepare the constructs used in group 1. In the course of further comparative studies, it might however be possible to reduce the time used for the cultivation of the constructs in group $2 \mathrm{~A}$. It is possible that the use of stem cells or certain cytokines such as bone morphogenetic protein-2, -4 , or -7 could provide shortcuts in the future. 
The ex vivo tissue-engineered combination of a collagen matrix and autologous periosteal cells and the ex vivo tissueengineered combination of NBM and autologous osteoblasts could be shown to be of value in sinus augmentation procedures with secondary implant placement. We gave this study the subtitle "steps into clinical application" because we were examining a limited number of procedures and patients. However, we suggest that, based on the present findings, future clinical trials are warranted.

\section{REFERENCES}

1. Springer, I. N., Terheyden, H., Geiss, S., Harle, F., Hedderich, J., and Acil, Y. Particulated bone grafts - effectiveness of bone cell supply. Clin Oral Implants Res 15, 205, 2004.

2. Block, M. S., and Kent, J. N. Sinus augmentation for dental implants: the use of autogenous bone. J Oral Maxillofac Surg 55, 1281, 1997.

3. Marx, R. E. Clinical application of bone biology to mandibular and maxillary reconstruction. Clin Plast Surg 21, 377, 1994.

4. Jensen, O. T., Shulman, L. B., Block, M. S., and Iacono, V. J. Report of the Sinus Consensus Conference of 1996. Int J Oral Maxillofac Implants 13, 11, 1998.

5. Young, M. P., Worthington, H. V., Lloyd, R. E., Drucker, D. B., Sloan, P., and Carter, D. H. Bone collected during dental implant surgery: a clinical and histological study. Clin Oral Implants Res 13, 298, 2002.

6. Fennis, J. P., Stoelinga, P. J., Merkx, M. A., and Jansen, J. A. Reconstruction of the mandible with a poly(D,L-lactide) scaffold, autogenous corticocancellous bone graft, and autogenous platelet-rich plasma: an animal experiment. Tissue Eng 11, 1045, 2005.

7. Nkenke, E., Weisbach, V., Winckler, E., Kessler, P., Schultze-Mosgau, S., Wiltfang, J., and Neukam, F. W. Morbidity of harvesting of bone grafts from the iliac crest for preprosthetic augmentation procedures: a prospective study. Int J Oral Maxillofac Surg 33, 157, 2004.

8. Engelke, W., Schwarzwaller, W., Behnsen, A., and Jacobs, H. G. Subantroscopic laterobasal sinus floor augmentation (SALSA): an up-to-5-year clinical study. Int J Oral Maxillofac Implants 18, $135,2003$.

9. Wiltfang, J., Merten, H. A., Schlegel, K. A., Schultze-Mosgau, S., Kloss, F. R., Rupprecht, S., and Kessler, P. Degradation characteristics of alpha and beta tri-calcium-phosphate (TCP) in minipigs. J Biomed Mater Res 63, 115, 2002.

10. Terheyden, H., Jepsen, S., Moller, B., Tucker, M. M., and Rueger, D. C. Sinus floor augmentation with simultaneous placement of dental implants using a combination of deproteinized bone xenografts and recombinant human osteogenic protein-1. A histometric study in miniature pigs. Clin Oral Implants Res 10, 510, 1999.

11. Warnke, P. H., Springer, I. N., Wiltfang, J., Acil, Y., Eufinger, H., Wehmöller, M., Russo, P. A. J., Bolte, H., Sherry, E., Behrens, E., and Terheyden, H. Growth and transplantation of a custom vascularised bone graft in a man. Lancet 364, 766, 2004.

12. Schimming, R., Hoffmann, M., and Schmelzeisen, R. Tissue engineering of autologous bone transplants. Possible indica- tions and clinical use in implantology. Schweiz Monatsschr Zahnmed 113, 1292, 2003.

13. Schimming, R., and Schmelzeisen, R. Tissue-engineered bone for maxillary sinus augmentation. J Oral Maxillofac Surg 62, 724, 2004.

14. Schmelzeisen, R., Schimming, R., and Sittinger, M. Soft tissue and hard tissue engineering in oral and maxillofacial surgery. Ann R Australas Coll Dent Surg 16, 50, 2002.

15. Wiltfang, J., Schlegel, K. A., Schultze-Mosgau, S., Nkenke, E., Zimmermann, R., and Kessler, P. Sinus floor augmentation with beta-tricalciumphosphate (beta-TCP): does platelet-rich plasma promote its osseous integration and degradation? Clin Oral Implants Res 14, 213, 2003.

16. Doglioli, P., and Scortecci, G. Characterization of endosteal osteoblasts isolated from human maxilla and mandible: an experimental system for biocompatibility tests. Cytotechnology 7, 39, 1991.

17. De Santis, D., Guerriero, C., Nocini, P. F., Ungersbock, A., Richards, G., Gotte, P., and Armato, U. Adult human bone cells from jaw bones cultured on plasma-sprayed or polished surfaces of titanium or hydroxylapatite discs. J Mater Sci Mater Med 7, 21, 1996.

18. Acil, Y., Springer, I. N. G., Broek, V., Terheyden, H., and Jepsen, S. Effects of bone morphogenetic protein-7 stimulation on osteoblasts cultured on different biomaterials. J Cell Biochem 86, 90, 2002.

19. Donath, K., and Breuner, G. A method for the study of undecalcified bones and teeth with attached soft tissues. The Säge-Schliff (sawing and grinding) technique. J Oral Pathol 11, 318, 1982.

20. Springer, I. N. G., Suhr, M., and Fleiner, B. Adaptive adjustment of the adolescent porcine mandibular condyle. Bone 31, 1190, 2002.

21. Wang, H., Springer, I. N., Schildberg, H., Acil, Y., Ludwig, K., Rueger, D. R., and Terheyden, H. Carboxymethylcellulosestabilized collagenous rhOP-1 device-a novel carrier biomaterial for the repair of mandibular continuity defects. J Biomed Mater Res 68A, 219, 2004.

22. Toriumi, D. M., O’Grady, K., Horlbeck, D. M., Desai, D., Turek, T. J., and Wozney, J. Mandibular reconstruction using bone morphogenetic protein 2: long-term follow-up in a canine model. Laryngoscope 109, 1481, 1999.

23. Schlegel, K. A., Kloss, F. R., Schultze-Mosgau, S., Neukam, F. W., and Wiltfang, J. Osseous defect regeneration using autogenous bone alone or combined with Biogran or Algipore with and without added thrombocytes. A microradiologic evaluation. Mund Kiefer Gesichtschir 7, 112, 2003.

24. Triplett, R. G., and Schow, S. R. Autologous bone grafts and endosseous implants: complementary techniques. J Oral Maxillofac Surg 54, 486, 1996.

25. Springer, I. N., Fleiner, B., Jepsen, S., and Acil, Y. Culture of cells gained from temporomandibular joint cartilage on nonabsorbable scaffolds. Biomaterials 22, 2569, 2001.

26. Puelacher, W. C., Mooney, D., Langer, R., Upton, J., Vacanti, J. P., and Vacanti, C. A. Design of nasoseptal cartilage replacements synthesized from biodegradable polymers and chondrocytes. Biomaterials 15, 774, 1994.

27. Puelacher, W. C., Vacanti, J. P., Ferraro, N. F., Schloo, B., and Vacanti, C. A. Femoral shaft reconstruction using 
tissue-engineered growth of bone. Int J Oral Maxillofac Surg 25, 223, 1996.

28. Puelacher, W. C. Gewebetechnologische Herstellung von Knorpel, Knochen und Sehnen, in Habiltationsschriften der Zahn-, Mund- und Kieferheilkunde. Berlin: Quintessenz Verlags-GmbH, 1996.

29. Schlegel, A. K., Donath, K., and Weida, S. Histological findings in guided bone regeneration (GBR) around titanium dental implants with autogenous bone chips using a new resorbable membrane. J Long Term Eff Med Implants 8, 211, 1998.

30. Schlegel, K. A., Sindet-Pedersen, S., and Hoepffner, H. J. Clinical and histological findings in guided bone regeneration (GBR) around titanium dental implants with autogeneous bone chips using a new resorbable membrane. J Biomed Mater Res 53, 392, 2000.

31. Zanetta-Barbosa, D., Klinge, B., and Svensson, H. Laser Doppler flowmetry of blood perfusion in mucoperiosteal flaps covering membranes in bone augmentation and implant procedures. A pilot study in dogs. Clin Oral Implants Res 4, 35, 1993.

32. Petrovic, L., Schlegel, K. A., Schultze-Mosgau, S., and Wiltfang, J. Different substitute biomaterials as potential scaffolds in tissue engineering. Int J Oral Maxillofac Implants 21, 225, 2006.

33. Springer, I. N. G., Terheyden, H., Dunsche, A., Czech, N., Tiemann, M., Hedderich, J., and Açil, Y. Collagen crosslink excretion and staging of oral cancer. Br J Cancer 88, 1105, 2003.

34. Lynn, A. K., Yannas, I. V., and Bonfield, W. Antigenicity and immunogenicity of collagen. J Biomed Mater Res 71B, 343, 2004.

35. Niemeyer, P., Krause, U., Punzel, M., Fellenberg, J., and Simank, H. G. Mesenchymal stem cells for tissue engineering of bone: 3D-cultivation and osteogenic differentiation on mineralized collagen. Z Orthop Ihre Grenzgeb 141, 712, 2003.

36. O'Brien, F. J., Harley, B. A., Yannas, I. V., and Gibson, L. J. The effect of pore size on cell adhesion in collagen-GAG scaffolds. Biomaterials 26, 433, 2005.

37. Wenz, B., Oesch, B., and Horst, M. Analysis of the risk of transmitting bovine spongiform encephalopathy through bone grafts derived from bovine bone. Biomaterials 22, 1599, 2001.

38. Benke, D., Olah, A., and Mohler, H. Protein-chemical analysis of Bio-Oss bone substitute and evidence on its carbonate content. Biomaterials 22, 1005, 2001.

39. Gruber, R., Sittinger, M., and Bujia, J. In vitro cultivation of human chondrocytes using autologous human serum supplemented culture medium: minimizing possible risk of infection with pathogens of prion diseases. Laryngorhinootologie $\mathbf{7 5}$, 105, 1996.

40. Acil, Y., Terheyden, H., Dunsche, A., Fleiner, B., and Jepsen, S. Three-dimensional cultivation of human osteoblast-like cells on highly porous natural bone mineral. J Biomed Mater Res 51, 703, 2000.

41. Terheyden, H., Jepsen, S., Moller, B., and Rueger, D. Sinus floor augmentation with simultaneous implant insertion using recombinant human osteogenic protein-1. Laryngorhino otologie 80, 47, 2001.

Address reprint requests to:

Ingo N. Springer

Department of Oral and Maxillofacial Surgery

University of Schleswig-Holstein

Campus Kiel

Arnold Hellerstr. 16

24105 Kiel, Germany

E-mail: springer@mkg.uni-kiel.de 